\title{
An Easy Gateway to Electrical Engineering Contents on an Institutional Repository
}

\author{
http://dx.doi.org/10.3991/ijoe.v9iS8.3376 \\ A.M.B. Pavani and G.P. Temporão \\ Pontifícia Universidade Católica do Rio de Janeiro, Rio de Janeiro, Brazil
}

\begin{abstract}
This work presents an overview of digital contents created in the different areas of a Brazilian Institution of Higher Learning and a solution that was implemented to make it easy to access items in Electrical Engineering - a significant part of it. Characteristics of the collection (types and numbers of contents) and the compliance to international standards and best practices are addressed too.
\end{abstract}

Index Terms - Digital Libraries, Electronic Theses and Dissertations, Institutional Repositories, Interactive Books, Learning Objects, Scholarly Communication.

\section{INTRODUCTION}

Universities all over the world have been using the Internet to make available different types of digital contents - some restricted to specific communities of users, others open to the public.

Clifford Lynch [1] defined an institutional repository (IR) as "a university-based institutional repository is a set of services that a university offers to the members of its community for the management and dissemination of digital materials created by the institution and its community members. It is most essentially an organizational commitment to the stewardship of these digital materials, including long-term preservation where appropriate, as well as organization and access or distribution.". His work was published after DSpace (http://www.dspace.org/), a free and open source product, was released by The Massachusetts Institute of Technology. Before DSpace and IRs, many institutions made their digital collections available from digital libraries. This was the case of PUC-Rio - Pontifícia Universidade Católica do Rio de Janeiro, as presented in section II.

Harnad and Brody [2] and Harnad et al [3] showed the importance of Open Access to digital contents in increasing citations and the impact of publications. This was when the Open Access Movement started.

Some years before these two events, ETD - Electronic Theses and Dissertations started being published. In 1997, they became a requirement at Virginia Tech - The Virginia Institute of Technology and State University [4]; a new genre of digital publications was created according to the authors. Currently, NDLTD - The Networked Digital Library of Theses and Dissertations (http://www.ndltd.org/) hosts a catalog with over 3 million metadata records of ETDs from all over the world. It can be found

http://thumper.vtls.com:6090/search/query;jsessionid=9F2 0A0745A00C4240A66DA79AC04152C?theme=NDLTD.
Another important service related to the availability of digital contents, based on Open Access and cooperation, is MERLOT - Multimedia Educational Resource for Learning and Online Teaching (http://www.merlot.org/). MERLOT is a repository of metadata on OA courseware whose authors voluntarily register on the system. This informs the ICT - Information and Communication Technology supported learning community.

\section{The Steps Followed AT PUC-Rio}

Management of digital contents at PUC-Rio began with a digital library of (of very simple hypermedia) courseware in Electrical Engineering - the Maxwell System (http://www.maxwell.lambda.ele.puc-rio.br/). It was deployed in 1995.

This system has been enhanced all over the years and now is referred to as an IR when digital contents are considered. A Learning Management System (LMS) was added to support face-to-face courses as well as distance ones. All content management of the LMS is managed by the IR module, yielding flexibility, share and reuse of digital materials.

Later on, new types of digital contents started being published - ETDs (2000), senior projects (2003), journals (2003), articles, videos and administrative documents. All areas of the university contribute to the collection. A set of Special Projects has also been made available, most of them in specific subjects and devoted to specific target audiences. The last significant enhancement of the system was the launching of version 4 that is accessible to the blind and the visually impaired.

Currently, there are almost 18,000 titles on the system. The two largest collections are those of ETDs and senior projects; they account for over 10,000 works in all areas of the university undergraduate and graduate courses.

An important feature of the system is that it is a data provider compliant to OAI-PMH - Open Archives Initiative Protocol for Metadata Harvesting (http://www.openarchives.org/). For this reason, metadata of all contents are collected to be transferred to national and international union catalogs.

\section{Digital Contents In EE}

Since the system started with the hosting of contents in Electrical Engineering and the system is still maintained and operated by EE, the digital collection has a significant number of items in this area; the variety of types is also bigger than in other areas. Table I presents an overview of the most significant items in the EE collection. 
TABLE I.

NUMBERS OF ITEMS IN THE EE COLLECTION BY TYPE

\begin{tabular}{|l|r|}
\hline \multicolumn{1}{|c|}{ Type of Content } & Number \\
\hline Electronic Theses and Dissertations & $1,110+$ \\
\hline Class Notes (texts) & 13 \\
\hline Assignments and Study Guides & 5 \\
\hline Senior Projects & 30 \\
\hline Interactive Books & 3 \\
\hline Interactive Exercises (in the books) & 685 \\
\hline Learning Objects & $13^{(1)}$ \\
\hline Videos & $28^{(2)}$ \\
\hline Assorted Learning Materials & $2,200+$ \\
\hline
\end{tabular}

(1) Four additional LOs are under development.

(2) There are additional 10 videos that need review.

Currently the number of items related to learning activities has been growing at a fast pace since there is a plan to cut the number of contact hours in undergraduate courses; online activities will substitute for them and courseware is of paramount importance.

An overview of the main types in the EE collection follows.

\section{A. ETDs and Senior Projects}

As shown in table I, ETDs are the largest set in the collection. Their number grows steadly due to the fact that ETDs became mandatory in August 2002 after becoming voluntary in 2000. The EE Graduate Program has retrospectively digitized the complete theses \& dissertations collection. The digital deposit of senior projects in EE became mandatory in August 2010.

Theses \& dissertations as well as senior projects have a three-fold role in the context of scholarly works. The first is that they are outputs of an educational level; the second is that they are inputs to the educational process; and the third is that they are documents that keep the memory of Institutions of Higher Education.

PUC-Rio is a member of both NDLTD and BDTD Biblioteca Digital de Teses e Dissertações (http://bdtd.ibict.br/), the Brazilian national consortium of ETDs.

\section{B. Articles and Research Reports}

Articles and research reports in EE are published in series. Two of them are thematic - Antennas and Computational Intelligence; the third covers miscellaneous subjects. The first series started in 2009. All three may contain preprints and postprints. The total number of articles is higher than 50 .

\section{Courseware}

Courseware were first items to be made available from the Maxwell System in 1995. In the almost 20 years since then, ICT has undergone an amazing change. This has led to a situation that all original contents, except one, were discarded. This one will have to be modified in order to "run smoothly".

Currently, the authors of this article have been engaged in the development of courseware to support two courses that will go from traditional face-to-face to partially online. This change will be implemented in the school term beginning in February 2014. For this to be possible, many items are already availble online, others are being reviewed, another set is under development and a fourth group is under final planning. The two courses are Signals \& Systems and Electric \& Electronic Circuits. The first belongs to the curricula of Computer Science, Computer Engineering, Control and Automation Engineering, Electrical Engineering and Nontechnology Engineering. The second is not in Computer Science and Nanotechnology Engineering.

The types of courseware $n$ EE are:

- Class Notes and Lab Guides are conventional text materials for "almost" linear reading. They are pdf files with references and links to simulators, websites, Learning Objects, etc. If the reader is online, he can connect to the external resource.

- Assignments are documents that contain sets of problems to be solved by the students. The sets are defined according to the topics in the syllabi and use internal and external links as tools to the solutions.

- Study Guides are documents that contain theoretical aspects of the syllabi along with problems to be solved by the students. They use internal and external links as tools to the solutions.

- Interactive Books in Electrical Engineering are the outcomes of a project that has been going on for more than a decade. In the beginning, the exercises were spread among different topics of the courseware of two courses. In order to facilitate access to the exercises, in 2008 they were organized in two books. The books were Circuitos Elétricos (Electric Circuits) and Sinais e Sistemas (Signlas \& Systems). Later, a third book was created - Controles $e$ Servomecanismos (Controls \& Servomechanisms). One of the main characteristics of the books is that they are divided in chapters according to texts books in each subject. At the same time, they have no text, since they are to be used with the courses text books. All exercises have, at least, three options of parameters and/or functions that are randomly selected each time an exercise runs. The current numbers of exercises are: 281 in Electric Circuits, 237 in Controls \& Servomechanisms and 167 in Signals \& Systems. The books are in OA.

- Learning Objects (LO) is a set of items, most of them animated and/or interactive, that contain theoretical considerations, practical information and an animated or interactive section; some contain little quizzes. The number of LOs available online is 13 . There are four more in different stages of development. This is a project under way and more LOs will be developed according to a strategy that has been defined $[6,7]$. The LOs are in OA.

- Circuits in Video is a set of videos (almost 40) that address the contents of the undergraduate Electric \& Electronic Circuits course. They mix recorded classes with whiteboard texts, graphics, etc. Students are supposed to watch an average of a little over two videos per week. The longest videos last about 25-30 minutes. The videos are in OA.

- Modules of Courses are hypermedia objects connecting the different smaller "grains" of contents (LOs, texts, study guides, etc). They are being implemented according to the syllabi. 
Since all digital contents are managed by the IR, they are all described according to the metadata set used on the system. This set is compliant to the Dublin Core Metadata Element Set (ISO 15836/2003) and to the best practices for specific types of contents.

\section{Digital Contents in Other AReas}

As mentioned in section II, the Maxwell System serves all areas of PUC-Rio. For this reason, almost $90 \%$ of the items are not related to EE. Most ETDs and senior projects come from other courses; all journals with more than one thousand articles are not related to EE either.

Such variety of contents and their numbers posed a problem to users who wanted EE contents only. The solution to this problem came with Elétrica On-line, presented in the next section.

\section{ELÉTRICA ON-LINE}

In order to make it easier to access contents related to EE, an interface called Elétrica On-line was implemented. It is an easy gateway to EE contents and information on the system. Figure 1 shows the opening page of this interface.

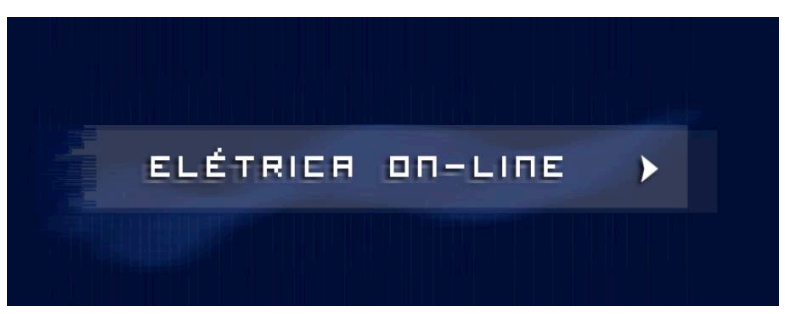

Figure 1. Opening page of Elétrica On-line.

Its objective is to yield easy access to all EE related digital contents available from the system. At the same time, it offers a set of links to other sites/systems that have EE or EE related materials.

The "links" in the links section of Elétrica On-line connect to different collections. Some examples are: (1) MERLOT that offers more that 400 EE contents among its almost 43 thousand items; (2) Books, such as Signals and Systems (http://cnx.org/content/col10064/latest),College Physics (http://openstaxcollege.org/textbooks/collegephysics) and Fast Fourier Transforms (http://cnx.org/content/col10550/latest/); (3) MOOC Massive Open Online Courseware, such as MIT OCW (http://ocw.mit.edu/index.htm) and Stanford Online (http://online.stanford.edu/); and (4) Applets, such as Educational Applets in Eleltrical Engineering (http://www.acsu.buffalo.edu/ wie/applet/applet.old),

Fourier Synhesis (http://www.nst.ing.tu-
bs.de/schaukasten/fourier/en idx.html) and Circuit Simulator Applet (http://www.falstad.com/circuit/).

An important comment must be made concerning the languages of most contents. It is English, though there is no restriction fromMERLOT to index contents in different languages. The other examples are all in English. Concerning the items that are available from the Maxwell System, the language is Brazilian Portuguese (over 99\% of the items).

\section{FINAL REMARKS}

The contents have been under development for many years. Many persons have contributed to them. The Interactive Books are considered as a collective authorship due to the many authors that have created the almost 700 exercises. This has been a remarkable team work of undergrads, graduate students, faculty and technical staff.

Currently, all courseware are in Portuguese. The Interactive Books, the Learning Objects and the Circuits in Video are indexed in MERLOT. It is important to remark that even though EE contents are accessed using Elétrica On-line, they maintain their original access from all other tools and search mechanisms of the system. An important aspect of Elétrica On-line is that it integrates digital contents in EE that were developed at the University along with others that are available worldwide in Open Access. The objective is to enhance accessibility.

This project is under way and, due to the possibilities of creating additional contents and exploring new technologies, it can go on for many years.

\section{REFERENCES}

[1] C. A. Lynch, "Institutional Repositories: Essential Infrastructure for Scholarship in the Digital Age", ARL, 226, 2003. Available http://www.arl.org/storage/documents/publications/arl-br-226.pdf.

[2] S. Harnad and T. Brody, "Comparing the Impact of Open Access (OA) vs non-OA Articles in the Same Journals", D-Lib Magazine, vol. 10, n. 6, 2004. Available http://www.dlib.org/dlib/june04/ harnad/06harnad.html.

[3] S. Harnad et al. "The Access/Impact Problem", Serials Review, vol.30, n. 4, pp. 310-314, 2004. Available http://www.ecs.soton. ac.uk/\%7Eharnad/Temp/impact.html. http://dx.doi.org/10.1016/j.serrev.2004.09.013

[4] "Fostering Learning in the Networked World: the Cyberlearning Opportunity and Challenge", Report of the NSF Task Force on Cyberlearning, Christine L. Borgman (chair), 2008. Available http://www.nsf.gov/pubs/2008/nsf08204/nsf08204.pdf.

[5] E. A. Fox, G. McMillan and J. L. Eaton, "The Evolving Genre of Electronic Theses and Dissertations", Proceedings of the $32^{\text {nd }}$ Annual Hawaii International Conference on Social Sciences, vol. Track 2, pp. 1-20, USA, 1997. Available http://www.ieeexplore. ieee.org/, http://dx.doi.org/10.1109/HICSS.1999.772646

[6] A. M. B. Pavani, "Concept Maps and Learning Objects - Part 1", Proceedings of the ICEED $2012-$ The $4^{\text {th }}$ International Congress on Engineering Education, pp 105-110, Malaysia, 2012.

[7] A. M. B. Pavani, "Concept Maps and Learning Objects - Part 2", Proceedings of the CISPEE - The $1^{\text {st }}$ International Conference of the Portuguese Society for Engineering Education, article 48, Portugal, 2013.

\section{AUTHORS}

A. M. B. Pavani is an Associate Professor of the Departamento de Engenharia Elétrica of PUC-Rio, Rio de Janeiro, RJ, 22451-900, Brazil (e-mail: apavani@) lambda.ele.puc-rio.br).

G. P. Temporão, is an Assistant Professor of the Centro de Estudos de Telecomunicações of PUC-Rio, Rio de Janeiro, RJ, 22451-900, Brazil (e-mail: temporao@opto.cetuc.puc-rio.br).

This article is an extended and modified version of a paper presented at the International Conference exp.at'13, held 18-20 September 2013, in Coimbra, Portugal. Submitted 18 November 2013. Published as resubmitted by the authors 04 December 2013. 